\title{
One Imagination in Experiences of Beauty and
}

\section{Achievements of Understanding}

Angela Breitenbach

Forthcoming in British Fournal of Aesthetics

\begin{abstract}
I argue for the unity of imagination in two prima facie diverse contexts: experiences of beauty and achievements of understanding. I develop my argument in three steps. First, I begin by describing a type of aesthetic experience that is grounded in a set of imaginative activities on the part of the person having the experience. Second, I argue that the same set of imaginative activities that grounds this type of aesthetic experience also contributes to achievements of understanding. Third, I show that my unified account of imagination has important implications: it sheds light on two puzzling phenomena, the aesthetic value of science and the cognitive value of art.
\end{abstract}

\section{Introduction}

Aestheticians and philosophers of mind have argued for the fundamental heterogeneity of the mental activities of imagination. Some have presented the diversity among different uses of imagination as self-evident. ${ }^{1}$ Kendall Walton, for example, famously

\footnotetext{
${ }^{1}$ E.g. Strawson, P.F., 'Imagination and Perception', in L. Foster and J. W. Swanson (eds), Experience and Theory (Amherst, MA: University of Massachusetts Press, 1970), 31-54; Walton, Kendall L., Mimesis as
} 
distinguishes different forms of imagining — spontaneous and deliberate, occurrent and nonoccurrent, solitary and social — before asking:

What is it to imagine? We have examined a number of dimensions along which imaginings can vary; shouldn't we now spell out what they have in common? Yes, if we can. But I can’t. (1990, 19)

Others have offered substantial arguments in support of the claim to heterogeneity. ${ }^{2}$ For example, Amy Kind compares the imaginative activities involved in mindreading, pretence, our engagement with fiction, and modal epistemology, and concludes that no single mental capacity can do all the explanatory work that has been assigned to the imagination in these different philosophical contexts. "Features of imagination that play an essential role in one context", she maintains, "drop out entirely in another context", and are sometimes even "inconsistent with features of imagination that play an essential role in another context" $(2013,157)$.

In this paper I offer considerations in support of a unified account of the mental activities of imagination. In particular, I argue against the heterogeneity of imagination

Make-Believe (Cambridge, MA: Harvard University Press, 1990); Stevenson, L., 'Twelve Conceptions of Imagination', British Fournal of Aesthetics, 43 (2003), 238-259.

2 E.g. Currie, G. and I. Ravenscroft, Recreative Minds: Imagination in Philosophy and Psychology (New York: Oxford University Press, 2002); Kind, A., 'The Heterogeneity of the Imagination', Erkenntnis 78 (2013), 141-159; Van Leeuwen, D.S. N. 2014. “The Meaning of 'Imagine' Part II: Attitude and Action”, Philosophy Compass, 9, 791-802. Van Leeuwen, D.S. N., “The Meaning of 'Imagine' Part I: Constructive Imagination", Philosophy Compass 8 (2013), 220-230. 
in two prima facie diverse contexts: experiences of beauty and achievements of understanding. More specifically, I show that there is a common core of imaginative activity that contributes to an important type of aesthetic experience and to the unification of cognitions necessary for understanding. If there is one imagination in such a diverse range of contexts, moreover, I suggest there is hope for a unified account of imagination in other areas as well.

I argue for my proposal by comparing the mental activities of imagination in aesthetic experiences and achievements of understanding in two entirely different domains, those of art and science. In Section 2, I focus on imagination as it contributes to aesthetic experience. I argue that there is a widespread type of aesthetic experience that is centrally reliant on the experiencer's imaginative engagement with the object of aesthetic appreciation. I illustrate this with the aesthetic experience of art before arguing that the same kind of experience occurs in the sciences as well. In Section 3, I turn to imagination as it contributes to achievements of understanding. I argue that the same kinds of imaginative activity that lie at the basis of the aesthetic experience I discuss in Section 2 also contribute to a necessary feature of achievements of understanding. I show how this plays out for understanding in science before arguing that the same kind of achievements are possible in our engagement with art as well. In Section 4, I offer further support for my proposal. I argue that acknowledging the unity of imagination in the contexts of aesthetic experience and achievements of understanding sheds light on two otherwise puzzling phenomena: the aesthetic value of science and the cognitive value of art. Experiences of beauty and achievements of understanding have at their 
basis one imagination, and this is why there is an intrinsic link between the aesthetic and cognitive dimensions of such human pursuits as art and science.

\section{Imagination and aesthetic experience}

My first claim is that there is a type of aesthetic experience that arises from the subject's imaginative reflection on the object. This type of aesthetic experience is not special to our engagement with art. It occurs across the arts and sciences.

Imagination and aesthetic experience of art. I begin with the more familiar context of art. Consider, in particular, an example from the performing arts: some years ago I saw Vollmond, a beautiful piece by Pina Bausch, the German choreographer of modern dance who died in 2009. What made the dance so beautiful was the way in which the apparently simple movements on stage intimated something recognisable, and perhaps universal, about human interactions and human emotions - in this case, about desire, about the ecstasies and cruelties of courtship, and about the fine line between humour and despair. The beauty of the dance had to do with the way in which a series of ordinary movements on a minimally decorated stage represented ideas about something so complex and often so incoherent as human experience and human emotion.

It is important to note that the achievement of Vollmond to communicate complex ideas was not that of enunciating a determinate meaning; and my experience of it was not that of deciphering a fixed code. The achievement of the performance, and my experience of it, required an imaginative involvement on my part. It relied on my 
drawing out ideas that were suggested, but only suggested and never made fully explicit, by the artwork itself. The show challenged me to think further. It prompted me to engage with ideas I found expressed in the performance, and to offer a variety of representations and interpretations to make sense of what I saw and heard. The beauty of the performance lay in pointing me to ideas of great significance whose content went beyond any particular representation of what was shown by the dance itself.

Abstracting from the particular case, I argue that one way in which works of art strike us as beautiful is by expressing ideas of general significance, where the ability of art to express such ideas centrally relies on the audience's imaginative reflection on the work. Dance performances, for instance, strike us as beautiful in this way, not simply because of our viewing of the dancers' bodies in carefully coordinated movements on stage, but because of the way in which in viewing the movements we find ourselves contemplating ideas that are of deep significance to us. Moreover, artworks succeed in expressing ideas in this way when the work provokes us to imaginatively reflect on what we see and hear in a way that is itself creative, and goes beyond any particular representation of what is strictly entailed by the artwork itself. For example, we appreciate a dance performance in this way when it seizes our attention and engages us to reflect on ideas that are undetermined, at least to some extent, by the dancers' movements, their spoken and sung words, their facial expressions, and the accompanying music or stage set. And this is so even though our engagement with the show is prompted by all these facets of the performance. At the heart of this kind of aesthetic experience, I suggest, thus lies the creative, imaginative reflection of the person having the experience. 
Dance performances are one species of artwork for which this description holds. Other artworks that may strike us as beautiful in this way include works of fiction, poetry, painting, sculpture, and music. ${ }^{3}$ They use different means including words and imagery, rhythm and rhyme, colour and composition, form and material, harmony and melody. But they all share the common feature that they can employ these means to suggest ideas and provoke our imagination in reflecting on those ideas. The important point to highlight among this variety, I suggest, is that at the heart of the aesthetic experience that these artworks can afford us lies the creative, imaginative reflection of the person having the experience.

This insight parallels a fundamentally Kantian idea: aesthetic pleasure arises from the imaginative reflection of the subject on the object. On Kant's account, such imaginative reflection consists in the 'free play' of imagination and understanding. ${ }^{4}$ In

${ }^{3}$ On the parallels in our engagement with literature, art and music, see Robinson, J., Deeper Than Reason: Emotion and Its Roles in Literature, Music, and Art (Oxford University Press, 2005). On fiction, see Currie, G., The Nature of Fiction (New York: Cambridge University Press, 1990); Friend, S., 'Imagining Fact and Fiction', in Kathleen Stock and Katherine Thomsen-Jones (eds) New Waves in Aesthetics (New York: Palgrave Macmillan, 2008), 150-169; Stock, K., 'Imagining and Fiction: Some Issues', Philosophy Compass 8 (2013), 887-896 and Only Imagine: Fiction, Interpretation, and Imagination (New York: Oxford University Press, 2017). On literature, see Lamarque, P. and S. Haugom Olsen, Truth, Fiction, and Literature: A Philosophical Perspective (Oxford: Oxford University Press, 1996). On music, see Walton, Kendall L., 'Projectivism, Empathy, and Musical Tension', Philosophical Topics 26 (1999), 407-440 and Kania, A., 'An Imaginative Theory of Musical Space and Movement', British Fournal of Aesthetics 55 (2015), 157-172.

${ }^{4}$ Kant, I., Critique of the Power of Judgment, transl. by Paul Guyer (Cambridge University Press, 2000), 103 (V 217). 
this play, imagination is free from the understanding in producing representations that are unconstrained by any particular concepts. In viewing Vollmond, for example, the imaginative representations I associate with the dance are never determinately captured by any particular interpretation of the performance. Imagination nevertheless works in harmony with the understanding by producing representations that can be conceptualised, even though they need not be conceptualised in any particular way. ${ }^{5}$ In viewing Vollmond, I may take my imaginative reflections to be suitable to the ideas expressed by the show, even if these ideas are never fully captured by any particular interpretation of the dance. More generally, for Kant this means that an artwork strikes us as beautiful when it makes possible an inexhaustible wealth of thoughts that are not fully determined by the artwork itself, yet adequate to what it expresses: an artwork "expand $[\mathrm{s}$...] the mind by setting the imagination free" and by connecting the representation of a concept with "a fullness of thought to which no linguistic expression is fully adequate". 6 The experience of beauty arises, Kant claims, from this open-ended play of our faculties.

I take this Kantian conception of the play of imagination and understanding to be exemplified by a variety of activities, in particular those that in the more recent aesthetics literature have been characterised as "exploratory", "fictive", "elaborative",

\footnotetext{
${ }^{5}$ For closer readings of Kant on imagination in aesthetics, see Gibbons, S L., Kant's Theory of Imagination: Bridging Gaps in Fudgement and Experience (Oxford University Press, 1994); Kneller, J., Kant and the Power of Imagination (Cambridge University Press, 2007); Matherne, S., 'Kant's Theory of the Imagination', in Amy Kind (ed), The Routledge Handbook of the Philosophy of Imagination (London: Routledge, 2016), 55-68. ${ }^{6}$ Kant, Critique of the Power of Judgment, 203-04/V 326
} 
"constructive", and "thematising" imaginings. ${ }^{7}$ Thus, an artwork may prompt me to imaginatively explore associations that can suitably be connected with the work. By focusing on certain aspects, and blending out others, I may take the show to suggest ideas of the central yet complicated role of desire in human relationships: the work may lead me to contemplate the playful but intense duets as games of playful seduction or as dangerous, perhaps coercive, encounters. The show may thereby prompt me to fictively imagine what the characters of the duets are going through, what their story is, and what they are feeling. It may stimulate in me a range of emotional states: I may be tense with suspense, agitated or curious as I watch the scene unfold.

An artwork may furthermore encourage me to imaginatively elaborate on what I take to be expressed by the work. In imaginatively filling in the details of the ideas I associate with Vollmond, I may picture the couple's background story, the way they came to meet, or the obstacles they had to overcome in order to be united. In viewing Bausch's

\footnotetext{
${ }^{7}$ On the exploratory, fictive, elaborative, constructive, and thematising imagination, see Savile, A., Aesthetic Reconstructions (Oxford: Basil Blackwell, 1988); Brady, E., 'Imagination and the Aesthetic Appreciation of Nature', The Journal of Aesthetics and Art Criticism 56 (1998), 139-147; Carroll, N. 2014. 'Creative Audience', in Elliot Samuel Paul and Scott Barry Kaufman, eds., The Philosophy of Creativity: New Essays, Oxford: Oxford University Press: 62-81. See also Gaut's discussion of experiential imaginings, which I take to be comparable to the case of fictive imaginings. Gaut, B., 'Creativity and Imagination', in Berys Gaut and Paisley Livingston (eds), The Creation of Art: New Essays in Philosophical Aesthetics (Cambridge University Press, 2003), 148-173, 153-5. Brady further distinguishes the revelatory imagination. As the following discussion will make clear, I believe that the various imaginative activities discussed here all contribute to revealing ideas to the audience; the revelatory function thus offers no distinct role of the imagination.
} 
duets, I may envision two budding lovers exhilarated by getting to know each other, yet wary about succeeding at their attempts at seduction; or I might picture a well-rehearsed couple of many years, nervously but decidedly aiming to rekindle their passion for one another.

Moreover, an artwork may prompt me to imaginatively construct a whole out of the ideas I take to be expressed by different parts of the work, and it may thereby suggest to me an overall theme. For example, I may see in Bausch's Vollmond the overall rendering of the romantic experiences of a multiplicity of couples, and I may think of Bausch's dance as unified by the idea that solitude and the desire for love go hand in hand. I believe that these various imaginative activities exemplify the contribution of imagination at the heart of the aesthetic experience I have described.

There is thus a type of aesthetic experience that is grounded in the achievement of an artwork to point to ideas that are of deep significance to whoever is appreciating the work; and the artwork's achievement to point to ideas in this way importantly relies on the audience's imaginative reflection on the work.

Imagination and aesthetic experience of science. I argue now that something similar goes on in another important context, namely, when we appreciate the beauty of more abstract intellectual entities such as scientific theories, proofs, and explanations. ${ }^{8}$ Extending the foregoing discussion shows that there is a type of genuine aesthetic

\footnotetext{
${ }^{8}$ For simplicity, I primarily focus on theories but what I say can easily be extended to scientific proofs and explanations.
} 
experience that occurs across the arts and sciences and that requires the audience's active imaginative engagement with the object of appreciation.

That one can extend my first claim in this way may be far from obvious. In fact, one might worry that there is a crucial difference between theories and artworks. Art engages our imagination, it may hint at how things are, and it may suggest how things should be. But it does not give us definitive answers; in fact, it rarely tells us what to think. Theories, by contrast, give a determinate account of the phenomena. They explain the data - at least they do so if they are somewhat successful. They therefore do not leave room for the same kind of indeterminate reflection required for the appreciation of artworks.

Or so one might object. On reflection, however, this contrast is not quite right. Compare my experience of Bausch's Vollmond with an example from the history of science. Werner Heisenberg, physicist and pioneer of quantum mechanics, describes an experience he had, one night on the island of Heligoland in May 1925, that exhibits some striking similarities with the aesthetic appreciation of artworks with which I have been concerned so far. The details of Heisenberg's science do not matter for my purposes. What matters is Heisenberg's aesthetic experience in proving a principle at the heart of the theory of quantum mechanics that he is in the process of formulating. Here is what he says:

When the first [mathematical] terms seemed to accord with the energy principle, I became rather excited, and I began to make countless arithmetical errors. As a result, it was almost three o'clock in the morning before the final result of my 
computations lay before me. The energy principle had held for all the terms, and I could no longer doubt the mathematical consistency and coherence of the kind of quantum mechanics to which my calculations pointed. At first, I was deeply alarmed. I had the feeling that through the surface of atomic phenomena, I was looking at a strangely beautiful interior, and felt almost giddy at the thought that I now had to prove this wealth of mathematical structure nature had so generously spread out before me. I was far too excited to sleep...

What I saw during that night in Heligoland was admittedly not very much more than the sunlit rock edge I had glimpsed in the autumn of $1924 .^{9}$

I take Heisenberg to be describing an aesthetic experience. His descriptions suggest that, in the process of carrying out a range of mathematical calculations, he felt a genuine pleasure. However, he did not simply take pleasure in discovering particular properties of his theory, or in the fact that his calculations were correct and were successful at proving the energy principle. The experience he describes has to do with his infant theory suggesting to him general and far-reaching insights into the structure of atomic phenomena, and yet only suggesting them. As Heisenberg puts it, by going through his computations, he felt as if he could see into "a strangely beautiful interior". His infant theory intimated to him important ideas about the phenomena, ideas he had not yet grasped in their entirety and that required further proof and spelling out. To appreciate their significance, he had to go beyond what was shown by the calculations

\footnotetext{
${ }^{9}$ Heisenberg, W., 'The Meaning of Beauty in the Exact Sciences', in his Across the Frontiers, transl. Peter Heath, (New York: Harper \& Row, 1974), 166-83, 75
} 
he had already completed. And he could only go beyond the insight offered by his completed calculations with the help of the imagination. I argue that the intimation of a strangely beautiful interior of the phenomena, and of a mathematical structure yet to be proven, centrally relied on Heisenberg's use of the imagination.

More generally, and abstracting from the particular example, I suggest that this kind of aesthetic experience in science, just as in art, arises in important respects from the subject's imaginative activities. A theory may prompt us to imaginatively explore ideas, for instance, by reflecting on the ways in which it accounts for particular phenomena, and by fictively imagining the plethora of particular situations for which it holds true. The theory may furthermore force us to imaginatively elaborate on how it fits in with our wider conception of the natural world, with other scientific theories and principles we hold true, and with potential new discoveries. It may thereby prompt us to imaginatively construct out of its various implications a more comprehensive conception of the universe; it may force on us an idea, even if not fully spelt out, of the cosmos, or nature, as a whole. Moreover, in suggesting such unifying ideas, the theory may lead us to recognise themes or patterns that can be rediscovered in a range of different areas of enquiry. I argue that, as in the case of art, these various activities illustrate the contribution of imagination at the heart of the aesthetic experience of science I have described. ${ }^{10}$

\footnotetext{
10 Discussions of imagination in science are thus directly relevant to more recent debates about the aesthetics of science. See, e.g. Hesse, M. B., Science and the human imagination. Aspects of the history and logic of physical science (Philosophical Library, New York, 1955); Boden, M. A., The Creative Mind: Myths and Mechanisms (London: Routledge, 2004); Thagard, P., The Cognitive Science of Science (Cambridge, MA: MIT Press, 2012).
} 
Even if one accepts this general parallel, however, one might worry about a certain disanalogy between my aesthetic experience of Bausch's Vollmond and the experience Heisenberg went through in the process of formulating his theory of quantum mechanics. The first example concerns the experience of an audience member, appreciating the performance of a show that was created by someone else. The second example is the experience of a scientist who is himself concentrated on working out a new theory. Should we not expect differences in the experiences, and the underlying mental activities of imagination, of the audience member and scientist?

I argue that any differences between the two cases do not detract from their commonality: they are differences of focus, not differences of kind. This is because the student grappling with Heisenberg's theory, and the historian of science appreciating Heisenberg's achievements, can go through the same imaginative processes, and with that the same aesthetic experience, as Heisenberg himself. In working through the theory, coming to understand its key ideas and its implications for particular phenomena, the student may be gripped by the deep significance of the ideas, perhaps not fully understood in their details but suggestive in their implications. The historian may be prompted to imaginatively construct more comprehensive ideas of nature that go beyond what the theory strictly implies. Equivalently, Pina Bausch may herself have undergone an aesthetic experience in choreographing Vollmond's powerful duets, just as I was impressed by their performance. Bausch may have been struck by the depth of ideas she found expressed by the dance, ideas that were not fully captured by any plans she might have had for the show she was in the process of developing. Bausch may thus herself have been prompted to associate a plethora of thoughts with the ideas she herself 
had wanted to express through her work. The choreographer just as the audience, and the science student just as the scientist, may thus reflect on artistic or scientific work, either during its production or as a finished product, in the imaginative way that contributes to aesthetic pleasure. And if this is true, then the same kind of aesthetic experience can equally be had by the person appreciating the art or science as by the artist or scientist herself.

There is thus a common element to my — and Bausch's — aesthetic appreciation of Vollmond and to Heisenberg's — and his student's - appreciation of the theory of quantum mechanics. It lies in the pleasure arising from the achievement of the dance or theory to point us to important and far-reaching ideas, an achievement that, in turn, relies on our imaginative reflection on the dance or theory.

\section{Imagination and achievements of understanding}

So far, I have argued that both artworks and theories strike us as beautiful when they force a range of imaginative activities on us. My second claim is that the same kinds of imaginative activity also contribute to achievements of understanding. As before, I show that such achievements characterise our engagement with art as well as science.

Imagination and understanding in science. I begin again with the more familiar context. This time, it is science, not art. But, first, let me come clear about two assumptions concerning the nature of understanding and its role in science. One is the simple and, I believe, uncontroversial thought that understanding nature is a goal of science. According to this assumption, providing understanding of natural entities and 
processes is an essential requirement for any successful theory: a good theory should not only be true but also provide us with an accessible grasp, or understanding, of such truths. There is, of course, more to this apparently simple assumption. Some philosophers think that one cannot gain more understanding without gaining more knowledge, and that the aim of understanding reduces to the aim of knowledge. ${ }^{11}$ Others believe that understanding is distinct from knowledge, and that we can gain more, or deeper, understanding without thereby knowing more. ${ }^{12}$ For the purpose of this paper, I stay clear of this debate and simply take for granted that understanding nature, whether reducible or irreducible to knowledge of nature, is an important intellectual goal of science.

The other assumption is the equally established thought that understanding is directed at a species of unification. ${ }^{13}$ Such unification may come in different forms. For

11 According to Lipton understanding is "simply more knowledge". Lipton, P., Inference to the Best Explanation (London: Routledge, 2004), 30. For others who argue that scientific understanding is a species of knowledge, see e.g. Grimm, S., 'Is Understanding a Species of Knowledge?' British Fournal for the Philosophy of Science 57 (2006), 515-535; Khalifa, K., 'Inaugurating Understanding or Repackaging Explanation?', Philosophy of Science 79 (2012), 15-37.

12 On the irreducibility of understanding to knowledge, see e.g. Zagzebski, L., 'Recovering Understanding', in M. Steup (ed), Knowledge, Truth and Duty (Oxford: Oxford University Press, 2001), 235-251; Elgin, C., 'Understanding the Facts’, Philosophical Studies 132 (2007), 33-42;

Hills, A., 'Understanding Why’, Noûs 49 (2015), 661-688; De Regt, H., 'Scientific understanding: Truth or dare?' Synthese 192 (2015), 3781-3797.

${ }^{13}$ See Grimm $(2012,105)$ who argues that 'if there is a common idea' among contemporary accounts of understanding it is that 'understanding is directed at a complex of some kind'. Grimm, S., 'The Value of Understanding', Philosophy Compass 7 (2012), 103-117. 
instance, it may consist in the unification of a variety of particular cases under a general principle or idea - e.g. when I understand that different optic appearances, such as rainbows and other meteorological phenomena, are the various effects of light, refracted and reflected through drops of water. Or it may consist in the unification of particular cases, subsumed under different general principles or ideas, in an overarching systematic framework - e.g. when I understand how the origin of rainbows fits in with a broader conception of the physics of optics and the physiology of colour vision. According to this second assumption, achievements of understanding consist in seeing how things hang together, how they relate to one another, or form part of a single system. One might object, again in line with the claim that understanding is a species of knowledge, that seeing relations between things is not enough to guarantee understanding. One might thus argue that even a highly systematic and unified scientific representation may turn out to be false, and that it is a further requirement of understanding that such a representation be true. Again, I need not adjudicate this further controversy here. I shall only assume that unification is a necessary feature of understanding nature.

Against these two background claims, let me come back to the imaginative activities I described earlier. As I have suggested, artworks as well as theories strike us as beautiful when they force a range of imaginative activities on us. And it is these same activities, I argue now, that also drive the unification that is central to understanding. Most obviously, perhaps, imagination contributes to the process of discovery. In reflecting on the natural phenomena we seek to explain, we may imaginatively explore ideas that unify the phenomena. And we may fictively imagine those ideas and project their 
implications on phenomena not yet studied. In so doing, we may come to see, for instance, how the vast plurality of atomic phenomena has the same inner structure, or how all material bodies attract all other material bodies. Moreover, and perhaps less obviously, imagination contributes not only to the process of discovery in reflecting on the natural phenomena to be explained. It is also involved in developing, testing, and selecting from among existing theories. This is because the formulation of new theories is usually a gradual and drawn-out process. It involves reflecting on existing ideas and principles, in particular, on earlier theories and on the successes and shortcomings of those theories in explaining the data. ${ }^{14}$ Even once new theories have been proposed, moreover, they do not always fully determine their implications for particular phenomena. Different components of scientific theories may have different and sometimes even contradictory implications. They may display a "looseness of fit" with the phenomena, and it may require further reflection to work out what can be explained or predicted on their basis. ${ }^{15} \mathrm{I}$ argue that the mental activities of imagination play a crucial role also in these contexts.

More specifically, in spelling out what exactly a theory implies for concrete cases, the activities of the exploratory and fictive imagination come into play. They consist in exploring interpretations of the abstract concepts a theory contains, and imaginatively

\footnotetext{
${ }^{14}$ E.g. Schaffer, S., 'Making Up Discovery', in M.A. Boden (ed), Dimensions of Creativity, (Cambridge, MA: MIT Press, 1994), 13-51.

${ }^{15}$ For an account, and some interesting examples, of this looseness of fit, see French, S., 'A ModelTheoretic Account of Representation', Philosophy of Science 70 (2003), 1472-1483; Bueno, O. and S. French, 'How Theories Represent', The British Fournal for the Philosophy of Science 62 (2011), 857-894.
} 
representing individual phenomena that may be unified under the concepts thus interpreted. In examining ideas expressed by a theory and in fictively imagining phenomena that fall under those ideas, we can thus specify what it entails for concrete cases. We can unify those cases under a general idea and thereby advance understanding.

In so doing, moreover, a theory may prompt us to imaginatively elaborate on particular situations that instantiate the theory. It may force us to imaginatively draw out the specific aspects of those situations, and to examine them in relation to other theoretical principles we hold true and take to be important. This imaginative activity is a further part of our ability to achieve and deepen understanding. Elaborating on the theory's fit with other scientific theories and insights brings about a form of unification: not of particulars under general principles, but of the theory with other parts of our theoretical commitments, and sometimes other theoretical principles that are yet to be confirmed. It thereby advances understanding of how different natural phenomena that are explained by different principles fit into a coherent theoretical system.

These imaginative activities may thereby also help us see how the theory can be developed further and what additional problems it might solve. By seizing the constructive and thematising imagination, a theory may prompt us to imagine how the plurality of its implications forms part of a single unified conception of nature, and it may lead us to view the diverse range of situations as governed by repeatable patterns, or themes. These activities, too, contribute to our attempts at achieving and increasing understanding of nature: they help us advance our grasp of how a diversity of particular natural phenomena can be combined in a single and cohesive unity. And they lead us 
to see how the same scientific principles apply in very different areas of enquiry - for example, how the same geometric principles govern the movements on earth as in the sky.

As these considerations show, there is an unexpected connection between aesthetic experiences in science and the scientist's aim of understanding: the same kind of imaginative activities that lie at the basis of the aesthetic experiences I have described also lead to the species of unification required for understanding. This contribution of the imagination is central not only for the often creative process of generating new theories, but also for the confirmation and defence of such theories. The mental activities of imagination play a role in both of the contexts that have traditionally been distinguished in $20^{\text {th }}$ century philosophy of science, the context of discovery and the context of justification. ${ }^{16}$ I take this to be another facet of a distinctively Kantian idea: the unifying and synthesizing activities of imagination at work in aesthetic experiences also underlie our cognitive activities. And these cognitive activities play a role both in formulating new concepts and principles and in applying such concepts and principles to particular phenomena. ${ }^{17}$

${ }^{16} \mathrm{On}$ an early version of the context distinction see, e.g., Reichenbach, H., Experience and Prediction. An Analysis of the Foundations and the Structure of Knowledge (Chicago: The University of Chicago Press, 1938). The relevance of the aesthetics of science in both contexts is also acknowledged, though for different reasons, by Cellucci, G., 'Mathematical beauty, understanding, and discovery', Foundations of Science, 20 (2014), 339-355; Ivanova, M., 'Aesthetic values in science', Philosophy Compass, 12 (2017).

17 Horstmann examines the relation of the imagination in Kant's theory of cognition and aesthetics. Horstmann, R.-P., Kant's Power of Imagination (Cambridge: Cambridge University Press, 2018.). See also 
My proposal of the intrinsic connection between experiences of beauty and achievements of understanding should not be mistaken for a stronger claim. According to this stronger claim, there exists a direct link between the beauty of a theory and its truth. By contrast, I do not argue that the activities of the exploratory, fictive, elaborative, constructive, and thematising imagination by themselves guarantee that the achievements of unification results in a truthful representation of the facts. To ensure truth, further empirical enquiry is needed. What I do argue is that the imaginative activities that provide the basis for the aesthetic experiences on which I focused in Section 2 are also sufficient for the unification necessary for understanding. Engaging in these imaginative activities is one way of achieving the unification that is so central to understanding. It is in this sense that imagination contributes to scientists' goal of understanding nature.

Imagination and understanding in art. It is not difficult to see now that the same connection between imagination and understanding also characterises our engagement with art. In the context of art, too, aesthetic appreciation and cognitive achievement are based on the same mental activities of imagination.

Consider, once again, the aesthetic experience I enjoyed when seeing Bausch's beautiful show Vollmond. As I suggested in the previous section, my experience of the show was grounded in important respects in my imaginative engagement with the work. Such engagement may consist, for example, in my imaginatively exploring ideas about the

\footnotetext{
Young, J. M., Kant's View of Imagination, Kant-Studien 79 (1988), 140-164; and Rosefeldt, T. 'Kant on the epistemic role of the imagination', Synthese (forthc.), 1-22.
} 
role of desire in human relationships, played out in particular in the intense duets incorporated in Bausch's show. It may consist furthermore in my fictively imagining details about the characters in those duets, what emotions they were going through, and how these emotions were expressed in the characters' comportment towards one another. It may involve my imaginatively elaborating on the details of the characters' stories, the way they came to meet, and the difficulties they had to master in order to find together. The various activities of imagination that may have contributed to my aesthetic experience also, I believe, contribute to a better understanding, for example, of the plurality of roles desire can play in human relationships. They may prompt me to see that desire can take different forms - playful, aggressive, or romantic - and have different functions in a partnership — unsettling, destructive, or stabilising. My imaginative engagement with Bausch's work can crystallise and unify existing conceptions; and it can make me become aware of forms of desire and their role in human relationships I had not previously recognised. In these various ways, the activities of imagination can advance the unification of cognition that is necessary for understanding. ${ }^{18}$

And there are other ways in which imagination is involved in the understanding we can gain through our engagement with art. My aesthetic experience of Vollmond may have been informed, for example, by my imaginatively constructing a narrative and

\footnotetext{
18 Elgin has given different reasons for the claim that dance can teach us and contribute to our understanding of the world. Elgin, G., 'Exemplification and the Dance', in Roger Pouivet (ed) Philosophie de la Dance (Rennes: Presses Universitaire de Rennes, 2010), 81-98. Unlike me she does not argue for the deep connection between aesthetic experience and the advancement of scientific understanding but instead relies on the capacity of dance to exemplify features of reality.
} 
conceptual whole out of the ideas I took to be expressed by different parts of the performance, and by my imaginatively following through an overall theme of the dance. For instance, I may think of Bausch's dance as unified by the idea that solitude and the desire for love go hand in hand. By combining in the imagination different components of the performance to this overarching theme, I may see deeper connections that I previously had not recognised. I may discover common threads and patterns in human experience that unify what, at first, appears complex and often incoherent. And if I do so, I advance the kind of unification that is central to achievements of understanding.

One might wonder, at this point, whether the understanding gained through our imaginative engagement with art is an emotional one only. ${ }^{19}$ By prompting me to engage with different representations of desire in human relationships, Bausch's dance may reinforce, and perhaps refine, existing emotions. The performance may encourage me to feel fear and anger at the sight of the aggressive display of desire; it may lead me to feel a sense of alarm in response to the representation of unpleasant sexual banter and outright terror in the face of displays of serious threats. Moreover, the performance may nurture new emotions I had not previously encountered. I may be encouraged to entertain an unusual mix of humour and despair I find represented by some of Bausch's characters. However, I believe my earlier examples have shown that the understanding that can be achieved through our imaginative engagement with art is not exclusively emotional; it can be genuinely cognitive. The imaginative activities that contribute to our aesthetic experience of art can contribute to a more unified conception of themes

\footnotetext{
${ }^{19}$ Carroll considers and rejects this proposal. Carroll, N., 'Aesthetics and the Educative Powers of Art', in Randall Curran (ed) A Companion to the Philosophy of Education (Oxford: Blackwell, 2003).
} 
and ideas we take to be expressed by the artwork. And this more unified conception, in turn, is an essential component of cognitive understanding.

Again, it is important to be clear about the strength of my claim. As in the case of science, the unified conception we may achieve through our imaginative engagement with art need not be a true representation of the facts. As before, a more unified and comprehensive grasp of an idea, and a more unified conception of its relation to other concepts we hold dear, is not necessarily a more accurate depiction of reality. It would need to be tested and held up against the facts. But it does give us a necessary ingredient for genuine understanding of the facts. It offers a better sense of what our ideas imply, what they mean and how they relate to one another. What the foregoing discussion has shown is thus that in engaging imaginatively with art, as with science, we can gain the kind of unification of cognition that is central to achievements of understanding. Through our engagement with art, I thus argue, we contribute to gaining a better understanding of the world.

The result is a surprising convergence: there is a common core to the mental activities of imagination in such apparently divergent contexts as experiences of beauty and advancements of understanding. And this is true for the domains of both art and science.

\section{The aesthetic value of science and the cognitive value of art}

So far I have argued for the unity of the imagination in experiences of beauty and achievements of understanding, and I have done so by pointing out parallels between the underlying imaginative activities in these two contexts. I now argue that my proposal 
receives further support from its implications: it promises a unified solution to two difficult problems, the problems of the cognitive value of art and the aesthetic value of science.

The cognitive value of art. What I have called 'the problem of the cognitive value of art' is really the difficulty of answering two distinct but closely related questions. The first concerns the very possibility that art could have cognitive import. Philosophers have pointed out that artworks do not construct arguments, offer evidence, or give reasons. They may suggest ideas, and intimate insights, but they do not commit to any claims about the world. These philosophers have therefore concluded that, while the aim of art is aesthetic reflection, it is fundamentally unsuited for the determinate representation of the real world. ${ }^{20}$ One might add furthermore that, insofar as artworks such as novels and films may appear to assert claims, these claims are not about reality but about fictional worlds. ${ }^{21}$ Artworks construct fictions, and any arguments, evidence, or reasons they may offer, must be understood in the context of these fictions. It thus appears that artworks not only avoid making determinate claims about reality, they even contravene any investigation of the real world. They aim at the construction of a world beyond

${ }^{20}$ E.g., Stolnitz, J., 'On the Cognitive Triviality of Art', British Fournal of Aesthetics 32 (1992), 191-200; Graham, G., 'Learning from Art'. The British Fournal of Aesthetics 35 (1995), 26-37;

Diffey, T. J., 'What Can We Learn from Art?' Australasian Fournal of Philosophy 73 (1995), 204-11. Gibson discusses this claim sceptically. Gibson, J., 'Cognitivism and the Arts', Philosophy Compass 4 (2008), 573589. Carroll discusses and ultimately rejects what he calls the 'no-evidence argument' and the 'noargument argument'. Carroll, 'Aesthetics and the Educative Powers of Art', 371-372.

${ }^{21}$ See Gibson's discussion of this further sceptical worry. Gibson, 'Cognitivism and the Arts', 6. 
reality, and are not in the business of uncovering truths. This, then, raises the first question: how can art have cognitive import at all?

Second, critics have argued that even if art could have cognitive import, a further question arises. It is natural to think that the special value of art lies in its being free from cognitive constraints. The purpose of art is not to represent reality but to offer opportunities for aesthetic contemplation, for engagement with fictional worlds and, as Kant had it, for the free play of our mental faculties. And this, one might maintain, is precisely what is unique, and especially valuable, about art. Even if art could provide new insights, its cognitive dimension would not be what sets it apart from other kinds of human pursuit. ${ }^{22}$ This raises the second question: why should we attribute to this cognitive dimension any value in our engagement with art?

I believe the account of the imagination I have developed in the previous sections offers a promising answer to these questions and to the sceptical worries that motivate them. In response to the first question, the previous discussion makes clear that art has an important cognitive dimension: it encourages the use of our imagination and, therewith, of activities that lie at the basis of genuinely cognitive achievements of understanding. To show this, I need not settle that the arguments offered in support of a sceptical answer to the first question are unsuccessful. Even if these arguments established that art cannot assert claims about the real world, it would not follow that art has no cognitive import. The cognitive import of art need not consist in the transfer

\footnotetext{
${ }^{22}$ For a discussion of this worry, see Gaut, Berys 'Art and Cognition', and Lamarque, Peter, 'Cognitive Values in the Arts: Marking the Boundaries', in M. Kieran (ed.) Contemporary Debates in Aesthetics and the Philosophy of Art (Oxford: Wiley-Blackwell, 2005).
} 
of truths, but can take a host of different forms. ${ }^{23}$ Some philosophers have argued, for example, that the cognitive import of art consists in the ability to illustrate and bring to light knowledge we already possess; ${ }^{24}$ the capacity to highlight the significance of values and practices we already adhere to; ${ }^{25}$ or the ability to expand and practice our cognitive capacities. ${ }^{26}$ Moreover, the argument I have developed in this paper brings to the table a compatible but distinct proposal, indeed, one that offers an account of how these various cognitive tasks may be accomplished by our engagement with art. As my discussion has shown, the cognitive import of art can consist in its prompting mental activities that contribute to achievements of understanding. And these, I have suggested, are the mental activities of imagination.

My proposal also offers a response to the second question. Even if we recognise the particularity of art, it does not follow that we should regard its cognitive dimension as irrelevant to its particular aesthetic status. By contrast, at least one aspect of this dimension is intrinsically connected to what makes art special. The cognitive dimension of art my proposal has identified is based on the very same mental activities of imagination that characterise its aesthetic dimension. The same mental activities of

${ }^{23}$ Gibson calls this general response a 'neo-cognitivist approach'. Gibson, 'Cognitivism and the Arts', 13.

${ }^{24}$ E.g. Eldridge, R., An Introduction to the Philosophy of Art (Cambridge: Cambridge University Press, 2005); Carroll, N., 'Art, Narrative, and Moral Understanding', in Jerrold Levinson (ed), Aesthetics and Ethics: Essays at the Intersection (Cambridge: Cambridge University Press, 1998), 126-60.

${ }^{25}$ E.g. Gibson, J., Fiction and the Weave of Life (Oxford: Oxford University Press, 2007).

${ }^{26}$ E.g. Novitz, D., Knowledge, Fiction and Imagination (Philadelphia, PA: Temple University Press, 1987). 
imagination that we value for the cognitive import of art are thus also central for its aesthetic value.

Let me come back to my aesthetic experience of the wonderful performance of Vollmond I saw a few years ago. The implications of my argument are not that, by experiencing the beauty of the dance, I train my cognitive capacities and become better at understanding such human emotions as humour and despair. My proposal implies rather that in experiencing the beauty of the show I rely on mental activities that also contribute to achievements of understanding. In imaginatively reflecting on the close link between experiences of laughter and the loss of hope, I activate the same mental capacities I employ in achieving more unified cognitions. It is part of the cognitive dimension of art that it prompts this kind of engagement. And since this part of the cognitive dimension of art is intrinsically linked to what makes art unique, we must value the ability of art to prompt our imaginative activities as part and parcel of the special status of art.

This conclusion does not imply that all cognitive responses to art are intrinsically linked to the aesthetic dimension of art. For example, we might learn historical information about the fate of women in $19^{\text {th }}$ century Norway from seeing a performance of Ibsen's Doll's House. Or, from the study of old paintings, we might gather evidence of the chemical processes that occur when colour pigments are exposed to light. Not all cognitive responses to art seem relevantly related to what makes art unique. Similarly, my proposal is compatible with the possibility that art is the object of an aesthetic appreciation that is different in kind from the aesthetic experience I have described. My proposal is therefore also compatible with the possibility that art is the object of aesthetic 
appreciation that is not intrinsically linked to any cognitive import. These qualifications highlight the limitations of what I have argued. But they are not detrimental to my proposal: art can have a cognitive dimension that is central to its value as a unique aesthetic pursuit.

The aesthetic value of science. What I have called 'the problem of the aesthetic value of science', too, arises from the difficulty of dealing with two distinct but related questions. First, some philosophers have questioned the supposed aesthetic status of experiences of the beauty or elegance of scientific theories. They have argued, for example, that such experiences are unlike genuine aesthetic experiences of artworks or natural landscapes because they are inadequately subjectively grounded and too closely linked to epistemic concerns; and they have claimed that judgments about the beauty of theories lack the disinterestedness required for aesthetic experiences. ${ }^{27}$ This raises the first question: are experiences of the beauty of theories genuine aesthetic experiences?

Second, even if theories can have aesthetic value, other philosophers have wondered why concerns for the aesthetic character of proofs or theories should play any role in scientific enquiry. ${ }^{28}$ It is true that aesthetic criteria are frequently cited as playing

27 See Zangwill, N., The Metaphysics of Beauty (Ithaca: Cornell University Press, 2007); Todd, C., 'Unmasking the Truth Beneath the Beauty'. International Studies in the Philosophy of Science 22 (2008), 6179. See also the older and less critical discussion in Kivy, Peter, 'Science and Aesthetic Appreciation' Midwest Studies in Philosophy 16 (1991): 180-95; Engler, G., 'Aesthetics in Science and Art', British Fournal of Aesthetics, 30 (1990), 24-33.

${ }^{28}$ The literature on this second controversy in philosophy of science is vast and diverse. See, e.g. Duhem, P., The aim and structure of physical theory (Princeton: Princeton University Press, (1954/1906); Kuhn, T. 
a justificatory role in science or, at least, as being indicative of true or empirically adequate theories. As the physicist Paul Dirac maintained, for example, a "theory with mathematical beauty is more likely to be correct than an ugly one." 29 But it is by no means obvious what links the aesthetic character of a theory with its truth. This raises the second question: what does the fact that we appreciate a particular theory aesthetically have to do with scientists' aim for good, or successful, theories?

The account of the imaginative contribution to experiences of beauty and achievements of understanding that I have spelt out in this paper offers a unified answer to both of these questions as well. In response to the first question, I argue that the aesthetic experience arises from the imaginative activities that are prompted by our engagement with the theory. They are not simply grounded in our experience of particular features of the theory, or in determinate claims about its epistemic success. ${ }^{30}$ This is why my proposal is compatible with the claim that aesthetic responses are

S., The Structure of Scientific Revolutions, 2nd edition (Chicago: The University of Chicago Press, 1970/1962); Sigman, J. and B. van Fraassen, 'Interpretation in Science and in the Arts', in G. Levine (ed) Realism and Representation (Madison: University of Wisconsin Press, 1993), 73-99; McAllister, J. Beauty and Revolution in Science (Ithaca: Cornell University Press, 1996); Bangu, S., 'Pythagorean Heuristic in Physics', Perspectives on Science, 14 (2007), 387-416. See also the papers collected in the more recent volume Bueno, O., G. Darby, S. French and D. Rickles (eds), Thinking about Science, Reflecting on Art: Bringing Aesthetics and Philosophy of Science Together (London: Routledge, 2017).

${ }^{29}$ Dirac, P. A. M., 'Can Equations of Motion Be Used in High-Energy Physics?', Physics Today 23 (1970), 29-31, 29.

${ }^{30}$ I thus disagree with those who attempt to reduce the beauty of theories to such features as simplicity or explanatory success. See e.g. McAllister, Beauty and Revolution in Science. 
subjective experiences that involve a disinterested pleasure. Again, the activities of imagination offer the crucial link between aesthetic experiences and understanding: aesthetic experiences are based on the same imaginative activities that contribute to cognitive advances; they are not, themselves, grounded in such cognitive advances.

Moreover, if the foregoing is right, we cannot escape a further conclusion in response to the second question. As we have seen, the aesthetic experiences I have described are based on activities of imagination that also lead to the unification necessary in gaining better understanding. The aesthetic experiences I have described occur whenever we are engaged in activities that also promote the scientist's aim of understanding. It follows that experiences of this kind present an experimental dimension of the search for understanding and may thus be taken as a sign for it. The aesthetic experiences I have been concerned with are not simply a by-product of science with no further relevance to scientific enquiry; they can perform an important heuristic function. Since such experiences indicate activities that promote the unification necessary for scientific understanding, they can guide us in our search for such understanding. And, as we have seen, they do not by themselves provide an infallible guide to truth. ${ }^{31}$ Exploring and elaborating on ideas imaginatively does not on its own

\footnotetext{
${ }^{31}$ In this respect I also disagree with those who draw a closer link between beauty and truth. See, e.g., Poincaré, H., Science and Method, transl. by Francis Maitland (London: T. Nelson and Sons, 1908); Chandrasekhar, S., Truth and Beauty: Aesthetics and Motivations in Science (Chicago: Chicago University Press, 1987). For more recent attempts to defend the link between beauty and truth, see also Kuipers, T., 'Beauty, A Road to the Truth', Synthese 131 (2002), 291-328; Montano, U., 'Explaining beauty in mathematics: An aesthetic theory of mathematics', Synthese Library 370 (2014), 220.
} 
guarantee that the representations thus unifying natural phenomena have the right relationship to the objects. Nevertheless, scientists have reason to take these aesthetic experiences seriously. For such experiences signal that they are on the right track at least in this sense: they are engaged in activities that contribute to scientific understanding. Aesthetic experiences of the kind I have described thus have a legitimate pull on scientists, not because such experiences link to truth claims, but because they offer a guide that we are genuinely engaged in the search for understanding.

My proposal is thus that there is a type of experience in science that has genuine aesthetic status and is relevant for scientific enquiry. This conclusion does not imply that all aesthetic judgments in science indicate the advancement of scientific understanding. There may be other claims about the beauty of theories, expressing responses that are not grounded in the imaginative activities I have described and that, therefore, are not linked to the unification required for scientific understanding. For instance, a scientist's judgment 'this theory is beautiful' may be a way of expressing that the theory is much simpler or displays more symmetry than its competitors. A judgment such as this would have no obvious function in guiding the search for scientific understanding; the appreciation of simple or symmetrical theories might be a enjoyable feature of doing science, but it would not have the heuristic role I have attributed to the aesthetic experiences discussed here. However, even if it can be shown that claims of this kind are genuine aesthetic judgments of a different kind, ${ }^{32}$ their possibility does not contradict

\footnotetext{
32 Some have argued that such determinate claims about the particular properties of theories cannot be genuine aesthetic judgments. See, e.g., Todd, 'Unmasking the Truth Beneath the Beauty'. By contrast with this, I have suggested that aesthetic judgments of this kind may be genuinely aesthetic, yet reducible
} 
the conclusion for which I have argued: that there is a kind of experience that is not only genuinely aesthetic but also specifically relevant for science. In fact, the contrast with other possible kinds of aesthetic response highlights an advantage of my approach. It shows that redirecting the focus from specific aesthetic properties of theories to the mental activities of imagination involved in reflecting on such theories is more promising for thinking about the role aesthetics can play in scientific enquiry.

My conclusion may nevertheless be met with scepticism. One might object that it is implausible to strongly link aesthetic experiences with scientific understanding. One might say that often the process of gaining understanding is anything but pleasurable; it is hard and painful. In response, I do not suggest that all cases of achieving scientific understanding have an aesthetic dimension. Sometimes the process of understanding may be so arduous that no mental energies are left to engage in the creative imaginative activities I have described. Understanding may be achieved in other ways; it may not always go hand-in-hand with the imaginative reflection that also lies at the basis of aesthetic experiences. Whether we will engage in such reflection will depend on the circumstances, for example, on whether we have the time or leisure to let the mind wander, are not too focused on solving difficulties of understanding or, by contrast, too distracted to focus on the problem at all. Many parts of science may be such that they do not leave room for the imaginative reflection that is required for aesthetic pleasure. Many tasks of the working scientist are comparatively dull, follow more or less mechanical procedures, or are so specialised that it is difficult for the scientist to grasp

to the kind I have focused on here. The reason is that often theories that are characterised by simplicity and symmetry prompt our imaginative engagement with science in the right way. See my xxx. 
the overall significance of her individual tasks. Whatever the circumstances, there may be cases where the achievement of understanding is hard and painful, and others where its progress is accompanied with the distinctive aesthetic experience I have described. The crucial insight that follows from the argument I have put forward is that where science does leave room for imagination and the aesthetic experiences it makes possible, there such aesthetic experiences are a sign that we are engaged in the mental activities that contribute to the advancement of understanding.

Let me come back to Heisenberg's description of his experience in Heligoland: the night in which he made a series of calculations that led him to the formulation of his theory of quantum mechanics. As I interpreted his notes in Section 2, Heisenberg's description points to the kind of aesthetic experience I have characterized, the experience of appreciating a theory as a profound and creative accomplishment that captures a deep insight about the phenomena, but that also forces us to recognise how incomplete this accomplishment is by pointing us beyond what it strictly implies. As I suggested, the beauty of Heisenberg's calculations lay in their revealing a deep insight about the phenomena while, at the same time, suggesting that what Heisenberg had achieved was only a dim glimpse of the much more far-reaching insights yet to be discovered, a hint of something that required further reflection and research. We can now see why Heisenberg was right to follow his aesthetic experience. He was right to heed his aesthetic sensitivity because it was also an indication of his seeking one of his main aims as a scientist, the aim of understanding the natural world around him. 


\section{Conclusion}

In this paper I have argued against the heterogeneity of the mental activities of imagination in two contexts: experiences of beauty and achievements of understanding. By focusing on the domains of art and science, I have shown that one unified imagination is central in these contexts. As I have shown, this conclusion is significant for understanding why we can attribute cognitive value to art and aesthetic value to science. We often gain unified cognition, and sometime genuine understanding, through art even though art can be appreciated for its own sake. The cognitive dimension of art is part and parcel of the value of art as a unique, aesthetic endeavour. Science can be genuinely aesthetically pleasing even though it aims at truth and understanding. The aesthetic dimension of science is intrinsically connected with its value as a cognitive enterprise. None of this is odd. And the reason why it is not is that the same imaginative activities are involved in aesthetic experiences and achievements of understanding. And if this is true for such diverse contexts as experiences of beauty and achievements of understanding, then there is reason to hope for a unified account of imagination that extends to other philosophical contexts as well. 